\title{
Letter to the Editor: Obesity and Inflammation: Change in Adiponectin, C-Reactive Protein, Tumour Necrosis Factor-Alpha and Interleukin-6 After Bariatric Surgery
}

\author{
Maureen McCormick
}

Published online: 24 October 2012

(C) Springer Science+Business Media New York 2012

To the Editor:

I have read with great interest the recent article by IllánGómez et al. describing their analysis of inflammation markers before and after bariatric surgery [1]. I was hoping that the research would add to the discussion of the role of inflammation in obesity previously described by others [2-4].

However, the statistical tests chosen to analyze the data do not on their face address the specific characteristics of the data set in two important ways: first, $t$ tests are used rather than analysis of variance for repeated measures, and second, the data, while not normally distributed, are analyzed with tests that assume a normal distribution. Further, the authors did not explain and defend the choices they made. Thus, the results and conclusions cannot be accepted as presented.

Regarding the first point, the $t$ test should only be used to analyze the results of a two-group study design [5] (p. 121). This study has one group. Further, the data-measurements of the markers of inflammation before surgery and at 3, 6 , and 12 months after surgery - are ideally suited for the more powerful repeated measures approach [5] (p. 333).

Regarding the second point, even a cursory look at the data presented in Table 3 should give the reader pause. Even at baseline, the distributions of all outcome variables appear seriously platykurtic. For example, the mean of C-reactive protein (CRP) is 26.19 , and its standard deviation is 23.17. This would seem to be an extremely flat curve. At 3 months post-surgery, the standard deviation of CRP is 4.8 points greater than the mean. The other three variables also appear skewed, and we cannot be assured that the assumption of normality has been met [5] (p. 97). If the data are non-normal, one can consider (a) using non- parametric tests or (b) using a logarithmic transformation to encourage the data into a normal distribution.

In addition, the distributions of the four outcome variables appear different. In some cases, for example, the standard deviation is greater than the mean, and in other cases, not. Thus, we cannot be assured that the assumption of the homogeneity of variance has been met [5] (p. 98).

I look forward to either (a) a defense of the techniques used or (b) the results from analysis using appropriate statistical tests.

Conflict of interest There are no conflicts of interest.

\section{References}

1. Illán-Gómez F, Gonzálvez-Ortega M, Orea-Soler I, et al. Obesity and inflammation: change in adiponectin, C-reactive protein, tumour necrosis factor-alpha and interleukin-6 after bariatric surgery. Obes Surg. 2012;22:950-5.

2. Holdstock C, Lind L, Engstrom BE, et al. CRP reduction following gastric bypass surgery is most pronounced in insulin-sensitive subjects. Int J Obes. 2005;29:1275-80.

3. Csendes A, Burgos AM, Roizblatt D, et al. Inflammatory response measured by body temperature, C-reactive protein and white blood cell count 1, 3, and 5 days after laparotomic or laparoscopic gastric bypass surgery. Obes Surg. 2009;19:890-3.

4. Habib P, Scrocco JD, Terek M, et al. Effects of bariatric surgery on inflammatory, functional and structural markers of coronary atherosclerosis. Am J Cardiol. 2009;104:1251-5.

5. Keppel G. Design and analysis: a researcher's handbook. 3rd ed. New Jersey: Prentice Hall; 1991.
M. McCormick ( $₫)$

1330 Beacon Street, Suite 203,

Brookline, MA 02446-3202, USA

e-mail:mem48@cornell.edu 